\title{
Pengaruh Pengetahuan Keuangan, Perilaku Keuangan, dan Pendapatan terhadap Kepuasan Keuangan
}

\author{
Cici Parwati Sari dan Hendra Wiyanto
}

\author{
Program Studi Manajemen Fakultas Ekonomi \& Bisnis \\ Universitas Tarumanagara \\ Email: cici.parwati2605@gmail.com
}

\begin{abstract}
The purpose of this study is to analyze the effect of financial knowledge, financial behavior, and income on Financial Satisfaction. The sample of this research is employees who work in the South Jakarta area. Samples were selected using a non-probability sampling method totaling 100 respondents by distributing questionnaires online using Google Forms. The analysis technique used is structural equation modeling supported by the smartPLS program version 3.2.8. the results obtained in this study are that there is a positive influence on financial knowledge, financial behavior, and income on financial satisfaction in employees in the south jakarta area.
\end{abstract}

Keywords: Financial Knowledge, Financial Behavior, Income, Financial Satisfaction

Abstrak: Tujuan dari penelitian ini adalah untuk menguji pengaruh Pengetahuan Keuangan, Perilaku Keuangan, dan Pendapatan terhadap Kepuasan Keuangan. Penelitian ini menggunakan sampel pada karyawan yang bekerja di wilayah Jakarta Selatan. Sampel dipilih dengan menggunakan metode non probability sampling yang berjumlah 100 responden dengan menyebarkan kuisioner secara online menggunakan Google Form. Teknik analisis yang digunakan structural equation modeling yang dibantu dengan program smartPLS versi 3.2.8. hasil yang didapat pada penelitian ini yaitu terdapat pengaruh positif pada pengetahuan keuangan, perilaku keuangan, dan pendapatan terhadap kepuasan keuangan pada karyawan di wilayah Jakarta Selatan.

Kata Kunci: Pengetahuan Keuangan, Perilaku Keuangan, Pendapatan, Kepuasan Keuangan

\section{LATAR BELAKANG}

Masyarakat indonesia yang memiliki hidup di lingkungan sosial, ekonomi dan keuangan yang berbeda harus bisa lebih bertanggung jawab pada kepuasan dan perlindungan keuangan untuk masa yang akan datang. Peningkatan harapan hidup dan kualitas hidup di negara maju dan berkembang menyebabkan karyawan mengambil lebih banyak tanggung jawab dari hari ke hari dan juga telah menjumlahkan kepuasan keuangan di tahun-tahun (Coskuner, 2016). Kepuasan adalah salah satu bentuk kebahagiaan yang di dapat seseorang dari hasil upaya yang telah dilakukan (Arifin, 2018). Salah satu bentuk rasa senang yang dimaksud yaitu dengan mencapai kepuasan keuangan.

Manulife (2016) menyimpulkan empat aspek, yaitu: (1) $70 \%$ mayoritas investor tidak memiliki nomor target selama deposit berjangka. (2) 53\% investor membelanjakan $70 \%$ atau lebih dari penghasilan mereka dalam per bulan. (3) investor membelanjakan $10 \%$ hingga $90 \%$ atau lebih dari gajinya, dan (4) $40 \%$ investor tidak memantau pengeluaran mereka sama sekali. Dengan berbagai kondisi keuangan dan lingkungan sosial yang berbeda pada setiap individu maka harus mengambil tanggung jawab yang lebih besar untuk mencapai masa depan yang lebih baik. 
Dalam penelitian ini, peneliti ingin lebih berfokus untuk mendalami faktor-faktor independen yang mempengaruhi kepuasan keuangan seperti, pengetahuan keuangan, perilaku keuangan dan pendapatan. Pengetahuan keuangan sangat dibutuhkan agar terhindar dari masalah keuangan yang bisa saja disebabkan dari rendahnya tingkat pendapatan. Pengetahuan keuangan juga sangat dibutuhkan untuk merespon berbagai perubahan dan peningkatan dunia keuangan yang terus terjadi disebabkan oleh beragam dan canggihnya produk dan jasa keuangan yang tercipta (Coskuner, 2016).

Perilaku keuangan didefinisikan sebagai perilaku manusia dalam hubungannya untuk mengelola keuangan (Xiao et al., 2016). Pendapatan merupakan total dari pendapatan rill seluruh anggota keluarga untuk memenuhi kebutuhan bersama maupun individu dalam keluarga (Dany \& Indra, 2019).

\section{KAJIAN TEORI}

Penelitian ini mengacu pada dua teori yaitu Theory of Planned Behavior dan Behaviorial Finance Theory. Teori perilaku terencana (Theory of Planned Behavior) merupakan suatu landasan teori yang dapat digunakan untuk memprediksi intensi perilaku tertentu dan menjadikan teori tersebut benar adanya. Theory of Planned Behavior (TPB) digunakan untuk meramalkan dan memahami pengaruh-pengaruh motivasional terhadap perilaku manusia, teori ini juga menyediakan kerangka penting dalam mempelajari sikap dan perilaku (Ajzen, 1991). Behaviorial Finance Theory merupakan analisis berinvestasi yang menggunakan ilmu psikologi dan ilmu keuangan, yaitu suatu pendekatan yang mejelaskan keaadan psikologi, sosiologi, ekonomi, dan keungan seseorang tersebut. Jadi, perilaku keuangan bermaksud untuk memahami perlaku seseorang dan dapat mengambil keputusan dalam bertindak.

Pengetahuan Keuangan menurut Durband et al., (2019) "financial knowledge, in this sense, refers to a basic understanding of financial concepts and procedures as well as the use of this knowledge to to solve financial problems". Peryataan tersebut menjelaskan bahwa dalam hal ini pengetahuan keuangan mengacu pada pemahaman dasar tentang konsep dan prosedur keuangan serta penggunaan pengetahuan ini untuk memecahkan masalah keuangan.

Perilaku Keuangan merupakan bagian dari perilaku ekonomi keuangan yang di dukung oleh teori-teori tentang perilaku keuangan ilmiah, dan yang lainnya psikologi dan sosiologi berusaha menjelaskan dan menemukan peristiwa-peristiwa yang tidak konsisten (Arifin et al., 2017).

Pendapatan menurut Schalembeir et al., (2018) "Income is an important predictor of life satisfaction. Not only because it allows people to improve their living standard, but also because it is often interpreted as an indication of one's position in society." Peryataan tersebut menjelaskan bahwa pendapatan prediktor penting pada kepuasan hidup. bukan hanya karena itu memungkinkan orang untuk meningkatkan standar hidup mereka, tetapi juga sering ditafsirkan sebagai indikasi posisi seseorang pada masyarakat.

Kepuasan Keuangan menggambarkan perbedaan antara keinginan seseorang dengan situasi keuangan yang sebenarnya (Coskuner, 2016). Seseorang dengan penghasilan yang cukup untuk memenuhi kebutuhan hidup maka akan merasa puas terhadap kondisi keuangan (Sheng, Kiak, dan Soon, 2013).

Pengetahuan Keuangan terhadap Kepuasan Keuangan. Pengetahuan keuangan sangat penting untuk diterapkan pada era sekarang karena dengan memiliki pengetahuan keuangan yang tinggi maka individu akan lebih bijak untuk memberikan keputusan mengenai keuangan 
mereka. Dengan mengelola pendapatan, membiasakan menabung, merencanakan dana pensiun dan investasi, dan membuat anggaran bagi seseorang untuk meningkatkan kemampuan keuangan mereka yang berkontribusi terhadap kepuasan finansial (Ali et al., 2015).

Perilaku Keuangan terhadap Kepuasan Keuangan. Perilaku keuangan mempelajari bagaimana manusia secara aktual berperilaku dalam menentukan sebuah keputusan dalam keuangan, khususnya dalam mempelajari bagaimana psikologi keputusan keuangan, perusahaan dan pasar keuangan (Wicaksono dan Dirvanda, 2015). Perilaku keuangan juga menjadi gambaran bagaimana seseorang dapat bersikap ketika dihadapkan dengan keputusan keuangan yang harus mereka ambil ( Chinen dan Endo, 2012).

Pendapatan terhadap Kepuasan Keuangan. Keuangan rumah tangga merupakan salah satu faktor penentu kepusan hidup dan kepuasan keuangan (Sarah dan Daniel, 2014). Untuk meningkatkan pendapatan diperlukan upaya yang berkesinambungan, dengan kata lain dengan menurunnya pendapatan yang dimiliki oleh individu maka akan menurunkan kepuasan keuangan. Dengan meningkatnya pendapatan yang diterima oleh individu maka akan meningkatkan peluang untuk merasakan kepuasan keuangan (Rahayu, 2019).

Kerangka pemikiran pada penelitian ini sebagai berikut:

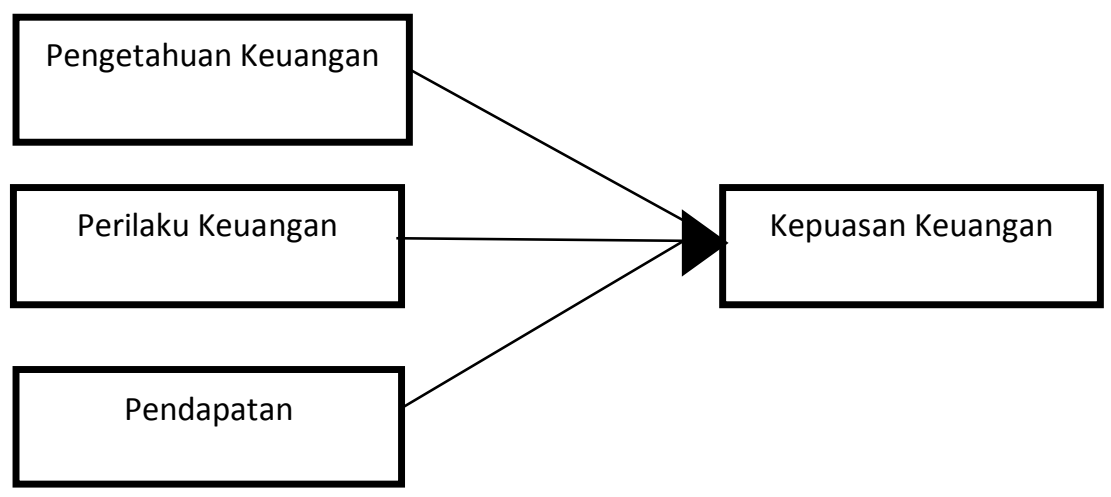

Gambar 1. Kerangka Pemikiran

Dari kerangka pemikiran diatas, maka terbentuk sebuah hipotesis yang akan diuji dalam masalah ini yaitu:

H1 : Pengetahuan Keungan berpengaruh positif terhadap Kepuasan Keuangan

H2 : Perilaku Keuangan berpengaruh positif terhadap Kepuasan Keuangan

H3 : Pendapatan berpengaruh positif terhadap Kepuasan Keuangan

\section{METODOLOGI}

Penelitian ini menggunakan desain penelitian deskriptif dengan metode kuantitatif. Populasi yang digunakan dalam penelitian ini adalah karyawan yang bekerja di wilayah Jakarta Selatan. Metode pengambilan sampel pada penelitian ini non probability sampling dengan teknik purposive sampling. Data yang dikumpulkan dengan menggunakan Google Form dengan menyebarkan kuisoner secara online dan melibatkan 100 responden. Skala yang digunakan untuk menggukur setiap indicator pada variabel penelitian ini menggunakan skala likert dengan skor 1-5.

Pada penelitian ini menggunakan model pengujian Structural Equation Modeling (SEM) dengan software Smart-PLS versi 3.2.8. Pengujian validasi dalam PLS berdasarkan convergent validity, Average Variance Extracted (AVE), Loading Factor. Pengujian reliabilitas berdasarkan hasil composite reliability dan Cronbach's Alpha dari masing-masing variabel. 
Uji outer model digunakan untuk melihat indikator dari variabel independen dalam penelitian. Ketentukan apakah semua indikator dapat dinyatakan valid dan realible dilihat dari masing-masing variabel berdasarkan loading factor dan AVE. jika hasil loading factor dan AVE $>0,5$, maka indikator tersebut di nyatakan sudah valid. Selanjutnya dilakukan uji model dengan memeriksa goodness of fit inner model. Pemeriksaan berdasarkan nilai determinasi total $\left(\mathrm{Q}^{2}\right)$ dengan cara menghitung $\mathrm{R}^{2}$ dari masing-masing variabel.

\section{HASIL UJI STATISTIK}

Pada penelitian ini menggunakan sampel sebanyak 100 responden yang merupakan karyawan di wilayah Jakarta Selatan, sebanyak 64 responden (64\%) merupakan perempuan dan 33 responden (33\%) merupakan laki-laki. Berdasarkan usia, sebanyak 99 responden (99\%) berusia 20-27 tahun, 1 responden(1\%) berusia 35-50 tahun. Berdasarkan dari segi domisili sebanyak 13 responden (13\%0 berdomisili di Jakarta Barat, 2 responden (2\%) berdomisili di Jakarta Timur, 62 responden $(62 \%)$ berdomisili di Jakarta Selatan, 6 responden (6\%) berdomisili Jakarta Utara, 1 responden (1\%) berdomisili di Jakarta Pusat. Berdasarkan dari pendidikan terakhir sebesar 61 responden berpendidikan SMA/Sederajat, 9 responden (9\%) berpendidikan Diploma, 30 responden (30\%) berpendidikan Sarjana. Berdasarkan dari pekerjaan sebesar 30 responden (30\%) berprofesi sebagai mahasiswa, 3 responden (3\%) berprofesi sebagai wirausaha, 67 responden (67\%) berprofesi sebagai karyawan. Dari 100 responden yang digunakan dapat diindikasi bahwa sampel yang digunakan valid dan reliable.

Uji validitas pada penelitian ini dengan melihat nilai convergent validity dan discriminant validity. Convergent validity adalah sejauh mana indikator dalam konstruk yang sama berkorelasi secara positif. Convergent validity dapat dilakukan dengan menghitung nilai outer loading factor setiap indikator dan nilai average variance extracted (AVE). Tabel 1. menunjukkan nilai AVE masing-masing variabel yang lebih besar dari 0,5 yang artinya memenuhi salah satu kriteria dari convergent validity.

Tabel 1. Hasil Analisis Average Variance Extracted (AVE)

\begin{tabular}{|c|c|}
\hline Variabel & AVE \\
\hline Pengetahuan Keuangan & 0,685 \\
\hline Perilaku Keuangan & 1,000 \\
\hline Pendapatan & 0,719 \\
\hline Kepuasan Keuangan & 0,677 \\
\hline
\end{tabular}




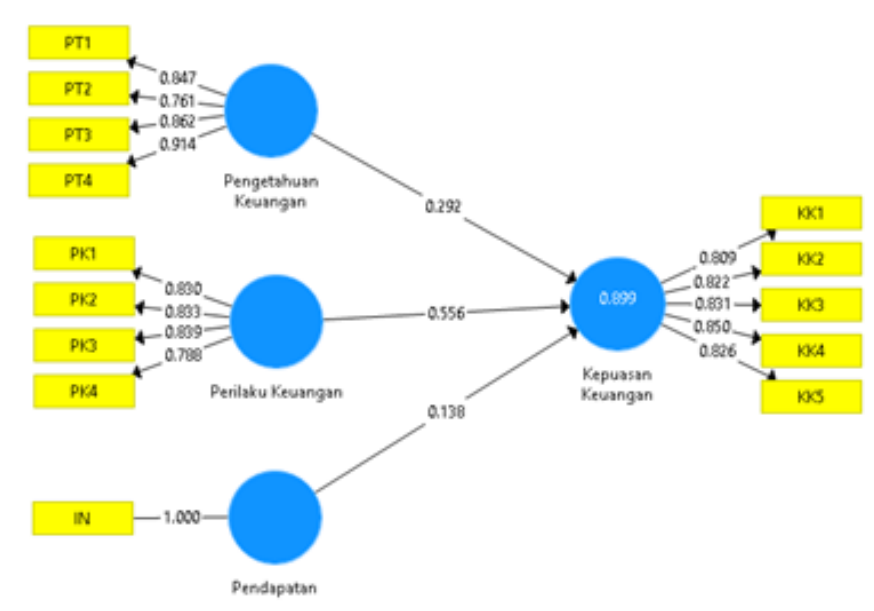

Gambar 1. Hasil Convergent Validity

Gambar 1 menunjukkan nilai loading factor masing-masing indikator pada penelitian ini. Nilai loading factor masing-masing indikator menunjukkan nilai diatas 0,5. Maka kriteria dari convergent validity dengan pendekatan nilai loading factor terpenuhi.

Tabel 2. Hasil Analisis Reliabilitas

\begin{tabular}{|c|c|c|}
\hline Variabel & Cronbach's Alpha & $\begin{array}{c}\text { Composite } \\
\text { Reability }\end{array}$ \\
\hline $\begin{array}{c}\text { Pengetahuan } \\
\text { Keuangan }\end{array}$ & 0,868 & 0,910 \\
\hline Perilaku & 0,841 & 0,894 \\
Keuangan & & \\
\hline Pendapatan & 1,000 & 1,000 \\
\hline
\end{tabular}

Tabel 2. di atas menunjukan nilai cronbach's alpha dan composite reliability masingmasing variabel yang diteliti memiliki nilai lebih besar dari 0,6. Maka variabel-variabel yang diteliti pada penelitian ini dapat dinyatakan reliabel.

Koefisien determinasi adalah ukuran dari akurasi prediksi sebuah model. Koefisien determinasi mewakili efek gabungan variabel eksogen pada variabel endogen, dengan kata lain koefisien determinasi bertujuan untuk melihat kontribusi variabel eksogen untuk memprediksi variabel endogen. Hasil koefisien determinasi akan ditampilkan pada tabel 3. berikut ini.

Tabel 3. Hasil Uji R-square

\begin{tabular}{|c|c|}
\hline Variabel & $\mathrm{R}^{2}$ \\
\hline Kepuasan Keuangan & 0,899 \\
\hline
\end{tabular}

Tabel 3 menunjukkan hasil uji $\mathrm{R}^{2}$ pada variable Kepuasan Keuangan sebesar 89,9\%, dapat dikatakan bahwa nilai $\mathrm{R}^{2}$ pada penelitian ini moderat. Berdasarkan hasil perhitungan goodness of fit yang dilakukan secara manual, maka dapat disimpulkan bahwa model yang digunakan dalam penelitian ini memiliki tingkat kecocokan yang tergolong besar yaitu 0,8320 . 
Tabel 4. Hasil Bootstrapping

\begin{tabular}{|c|c|c|c|}
\hline \multirow{2}{*}{ Variabel } & \multicolumn{3}{|c|}{ Kepuasan Keuangan } \\
\cline { 2 - 4 } & Path Coefficients & t-stat & p-values \\
\hline $\begin{array}{c}\text { Pengetahuan keuangan => } \\
\text { Kepuasan keuangan }\end{array}$ & 2,697 & 2,624 & 0,004 \\
\hline $\begin{array}{c}\text { Perilaku keuangan => } \\
\text { Kepuasan keuangan }\end{array}$ & 4,845 & 4,694 & 0,000 \\
\hline $\begin{array}{c}\text { Pendapatan => kepuasan } \\
\text { keuangan }\end{array}$ & 2,447 & 2,569 & 0,005 \\
\hline
\end{tabular}

Berdasarkan hasil pengujian bootstrapping bahwa pengetahuan keuangan, perilaku keuangan, dan pendapatan memiliki pengaruh positif terhadap kepuasa keuangan. Jiki melihat dari nilai P-values sebesar 0,004 PT -> KK. Sebesar 0 PK->KK. Sebesar 0,005 IN -> KK.

\section{DISKUSI}

Dari hasil diatas, maka dapat disimpulkan bahwa penelitian ini sudah valid dan reliable karena telah lolos semua pengujian yang ada pada program smart-PLS versi 3.2.8. hasil penelitian tersaji pada table 4. Hipotesis pertama bahwa pengetahuan keuangan berpengaruh positif terhadap kepuasan keuangan terbukti. Artinya semakin baik pengetahuan keuangan seseorang maka akan semakin baik tingkat kepuasan keuangan individu (H1 diterima). Hipotesis kedua bahwa perilaku keuangan berpengaruh positif terhadap kepuasan keuangan terbukti. Artinya Semakin baik perilaku keuangan individu maka akan semakin puas dengan kondisi keuangannya (H2 diterima). Hipotesis ketiga bahwa pendapatan berpengaruh positif terhadap kepuasan keuangan terbukti. Artinya jika memilki tingkat pendapatan yang baik akan memberikan kepuasan keuangan tersendiri terhadap individu (H3 diterima).

Hasil penelitian ini sejalan dengan Ann dan Cliff (2016) bahwa kepuasan finansial sebagai komponen penting bagi kepuasan dan kesejahteraan hidup konsumen. Penelitian yang dilakukan Halim dan Astuti (2015) menyatakan bahwa terdapat pengaruh yang signifikan antara pengetahuan keuangan terhadap kepuasan keuangan, hal itu menyebabkan bahwa semakin tinggi pengetahuan individu dalam keuangan maka akan tingkat kepuasan keuangan individu akan semakin tinggi. Robb dan Woodyyard (2018) bahwa perilaku keuangan berpengaruh positif terhadap kepuasan keuangan. Semakin baik perilaku keuangan yang dimiliki individu maka akan merasa puas terhadap kondisi keuangannya dan siap dalam mengelola keuangan.

Penelitian yang dilakukan Fajar dan Mulia (2019) bahwa pendapatan memiliki pengaruh yang signifikan terhadap kepuasan keuangan, penelitian tersebut menyatakan bahwa semakin tinggi pendapatan maka semakin banyak konsumsi untuk memenuhi keinginan pribadi, oleh karena itu semakin tinggi kepuasan finansial maka akan semakin meningkat konsumsi yang di inginkan. Jumlah pendapatan memiliki pengaruh yang paling besar atas kepuasan keuangan seseorang (Coskuner, 2016).

\section{PENUTUP}

Penelitian ini bertujuan untuk mengetahui dan menganalisis berapa besar pengaruh pengetahuan keuangan, perilaku keuangan, dan pendapatan terhadap kepuasan keuangan pada karyawan. Dalam penelitian ini dapat disimpulkan bahwa : (1) Pengetahuan keuangan berpengaruh positif terhadap kepuasan keuangan. (2) Perilaku keuangan berpengaruh positif terhadap kepuasan keuangan. (3) Pendapatan berpengaruh positif terhadap kepuasan keuangan

Adapun saran yang dapat disampaikan yaitu: (a) Untuk penelitian selanjunya agar saat pembagian kuisioner bias disebarkan lebih luas lagi supaya biasa menambah jumlah responden, karena cangkupan untuk wilayah Jakarta selatan cukup luas. (b) Dalam penelitian 
ini hanya memiliki empat variabel yang digunakan untuk mengetahui tingkat kepuasan keuangan pada karyawan di wilayah Jakarta selatan. Diharapkan bagi peneliti selanjutnya agar bias menambahkan variabel lain yang dapat di uji secara teoritis berpengaruh terhadap kepuasan keuangan.

\section{DAFTAR PUSTAKA}

Ahmisuhaiti, K., Ahmad, K., Hassan, R., \& Idris, F. (2017). Influence of Financial Literacy on Financial Satisfaction with Financial Behavior as Moderating Variable. Asian Journal of Technical Voational Education And Training, 2, 1-9.

Ajzen, I. (1991). The theory of planned behavior. Organizational Behavior and Human Decision Processes. https://doi.org/10.1016/0749-5978(91)90020-T

Ali, A., Rahman, M. S. A., \& Bakar, A. (2015). Financial Satisfaction and the Influence of Financial Literacy in Malaysia. Social Indicators Research, 120(1), 137-156. https://doi.org/10.1007/s11205-014-0583-0

Andrew, V., \& Linawati, N. (2014). Hubungan Faktor Demografi dan Pengetahuan Keuangan Dengan Perilaku Keuangan Karyawan Swasta di Surabaya. Finesta.

Ariani, D., Utami, H., \& Susilo, H. (2013). PENGARUH KEPUASAN KERJA DAN MOTIVASI KERJA TERHADAP PRESTASI KERJA KARYAWAN (Studi Pada PT. Inti Luhur Fuja Abadi (ILUFA), Pasuruan). Jurnal Administrasi Bisnis S1 Universitas Brawijaya, 1(1), 123-131.

Asna, H. A. (2017). Pengaruh Dewan Komisaris Independen, Kepemilikan Manajerial, dan Kepemilikan Institusional Terhadap Kinerja Perusahaan Pada Perusahaan Manufaktur. Artikel Ilmiah.

Chinen, K., \& Endo, H. (2012). Effects of Attitude and Background on Personal Financial Ability: A Student Survey in the United States. International Journal of Management, $29(1), 33$.

Coşkuner, S. (2016). Understanding Factors Affecting Financial Satisfaction: The Influence of Financial Behavior, Financial Knowledge and Demographics. Imperial Journal of Interdisciplinary Research, 2(5), 2454-1362.

Danns, D. E. (2019). Durband, D., Law, R. \& Mazzolini, A. (Eds.). (2019). Financial counseling. Cham, Switzerland: Springer Nature Switzerland AG. ISBN: 9783319725857. 235 pp. (hardcover). Family and Consumer Sciences Research Journal. https://doi.org/10.1111/fcsr.12306

Darmawan, D., \& Pamungkas, A. S. (2019). Pengaruh Financial Attitude, Financial Behavior, Dan Financial Knowledge Terhadap Financial Satisfaction. JEMMA | Journal of Economic, Management and Accounting, $2(2), \quad 9$. https://doi.org/10.35914/jemma.v2i2.243

Dwiandana Putri, A., \& Setiawina, D. (2013). Pengaruh Umur, Pendidikan, Pekerjaan Terhadap Pendapatan Rumah Tangga Miskin Di Desa Bebandem. E-Jurnal Ekonomi Pembangunan Universitas Udayana, 2(4), 173-180.

Erwin, P., \& Karmini, N. (2012). Pengaruh Pendapatan, Jumlah Anggota Keluarga, Dan Pendidikan Terhadap Pola Konsumsi Rumah Tangga Miskin Di Kecamatan Gianyar. EJurnal Ekonomi Pembangunan Universitas Udayana, 1(1), 39-48.

Falahati, L., Sabri, M. F., \& Paim, L. H. J. (2012). Assessment a model of financial satisfaction predictors: Examining the mediate effect of financial behaviour and financial strain. World Applied Sciences Journal, 20(2), 190-197. https://doi.org/10.5829/idosi.wasj.2012.20.02.1832

Garret, J. J. (2003). The Elements of User Experience: User-Centered Design for the Web and Beyond, Second Edition. In Interactions. https://doi.org/10.1145/889692.889709 
Gerrans, P., Speelman, C., \& Campitelli, G. (2014). The Relationship Between Personal Financial Wellness and Financial Wellbeing: A Structural Equation Modelling Approach. Journal of Family and Economic Issues, 35(2), 145-160. https://doi.org/10.1007/s10834-013-9358-z

Ghozali, I. (2016). Ghozali, Imam. (2016). Aplikasi Analisis Multivariate dengan Program IBM SPSS 23. Semarang: BPFE Universitas Diponegoro. IOSR Journal of Economics and Finance. https://doi.org/https://doi.org/10.3929/ethz-b-000238666

Grable, J. E., Park, J. Y., \& Joo, S. H. (2009). Explaining financial management behavior for koreans living in the united states. Journal of Consumer Affairs. https://doi.org/10.1111/j.1745-6606.2008.01128.x

Hair, J. F., Ringle, C. M., \& Sarstedt, M. (2011). PLS-SEM: Indeed a silver bullet. Journal of Marketing Theory and Practice, 19(2), 139-152. https://doi.org/10.2753/MTP10696679190202

Halim, Y. K. E., \& Astuti, D. (2015). Financial Stressors, Financial Behavior, Risk Tolerance, Financial Solvency, Financial Knowledge, dan Kepuasan Finansial. Jurnal Finesta, 3(1), 19-23. https://doi.org/10.1109/EDOC.2009.26

Hasibuan, B. K., Lubis, Y. M., \& HR, W. A. (2018). Financial Literacy and Financial Behavior as a Measure of Financial Satisfaction. 46(Ebic 2017), 503-507. https://doi.org/10.2991/ebic-17.2018.79

Henseler, J. (2010). On the convergence of the partial least squares path modeling algorithm. Computational Statistics. https://doi.org/10.1007/s00180-009-0164-X

Herdjiono, I., Damanik, L. A., \& Musamus, U. (2016). Pen Gar Uh Fi Na Nci Al a Tti Tu De, Fi N Anc Ial K Now Le Dge , Par Ent Al in Co Me Te Rh Ada P Fin a Nci Al Ma Nag Em Ent. Manajemen Teori Dan Terapan, 1(3), 226-241.

Hill, R. J., Fishbein, M., \& Ajzen, I. (1977). Belief, Attitude, Intention and Behavior: An Introduction to Theory and Research. Contemporary Sociology. https://doi.org/10.2307/2065853

Humaira, I., \& Sagoro, E. M. (2018). Pengaruh Pengetahuan Keuangan, Sikap Keuangan, Dan Kepribadian Terhadap Perilaku Manajemen Keuangan Pada Pelaku Umkm Sentra Kerajinan Batik Kabupaten Bantul. Nominal, Barometer Riset Akuntansi Dan Manajemen, 7(1). https://doi.org/10.21831/nominal.v7i1.19363

Kholilah, N. Al, \& Iramani, R. (2013). STUDI FINANCIAL MANAGEMENT BEHAVIOR PADA MASYARAKAT SURABAYA. Journal of Business and Banking. https://doi.org/10.14414/jbb.v3i1.255

Lee, N. R., \& Miller, M. (2012). Influencing positive financial behaviors: The social marketing solution. Journal of Social Marketing. https://doi.org/10.1108/20426761211203265

Maechler, M., Struyf, A., Hubert, M., Hornik, K., Studer, M., \& Roudier, P. (2015). Package 'cluster': Cluster Analysis Basics and Extensions. $R$ Topics Documented. https://doi.org/ISBN 0-387-95457-0

Nugraha, D. F., Pratama, I. M., \& Kustiawan, M. (2020). Financial Satisfaction Increase: Effect of Income and Financial Literacy Factors (Study of MSMEs). 400(Icream 2019), 320-322. https://doi.org/10.2991/assehr.k.200130.193

Pambudi, Bagus., Handayani, K. 2014. (n.d.). Analisis Kesesuaian Desain Rumah Terhadap Konsep Greenship Home Pada Perumahan Menengah Ke Atas Di Kota Gresik Gandhi Bagus Pambudi. 1-7.

Park, N., Kim, Y. C., Shon, H. Y., \& Shim, H. (2013). Factors influencing smartphone use and dependency in South Korea. Computers in Human Behavior. https://doi.org/10.1016/j.chb.2013.02.008

Plagnol, A. C. (2011). Financial satisfaction over the life course: The influence of assets and liabilities. Journal of Economic Psychology. https://doi.org/10.1016/j.joep.2010.10.006

Ramadhan, A. Y., \& Asandimitra, N. (2019). Determinants of Financial Management Behavior 
of Millennial Generation in Surabaya. Jurnal Minds: Manajemen Ide Dan Inspirasi, 6(2), 129. https://doi.org/10.24252/minds.v6i2.9506

Ricciardi, V. (2008). The Psychology of Risk: The Behavioral Finance Perspective. Handbook of Finance, September 2008, 269-292. https://doi.org/10.1002/9780470404324.hof002010

Roscoe, J. T. (1975). Fundamental research statistics for the behavioural sciences (2nd Edition). In Holt Rinehart \& Winston, New York.

Sekaran, U., \& Bougie, R. (2011). Research Methods for Business: A Skill-Building Approach, 6th Edition.

Sekaran, U., \& Bougie, R. (2016). Reserach Methods for Bussiness A Skill-Bulding Approach. Printer Trento Srl.

Teoh, W. M. Y., Chong, S. C., Lin, B., \& Chua, J. W. (2013). Factors affecting consumers' perception of electronic payment: An empirical analysis. Internet Research, 23(4), 465485. https://doi.org/10.1108/IntR-09-2012-0199

Vera-Toscano, E., Ateca-Amestoy, V., \& Serrano-del-Rosal, R. (2006). Building financial satisfaction. Social Indicators Research. https://doi.org/10.1007/s11205-005-2614-3

Wetzels, M., Odekerken-Schröder, G., \& Van Oppen, C. (2009). Using PLS path modeling for assessing hierarchical construct models: Guidelines and empirical illustration. MIS Quarterly: Management Information Systems. https://doi.org/10.2307/20650284

Wicaksono, E. D. (2015). Pengaruh Financial Literacy Terhadap Perilaku Pembayaran Kartu Kredit Pada Karyawan di Surabaya. Finesta.

Wiharyo, S., \& Budiarti, A. (2017). Kepuasan Sebagai Mediasi Pengaruh Kualitas Layanan Dan Harga Terhadap Loyalitas Penumpang Citilink. Issn : 2461-0593, 6(3).

Woodyard, A. S., \& Robb, C. A. (2016). Consideration of Financial Satisfaction: What Consumers Know, Feel and Do from a Financial Perspective. Journal of Financial Therapy, 7(2). https://doi.org/10.4148/1944-9771.1102

Wulandari, \& Aprilia, S. (2015). Jurnal TAM ( Technology Acceptance Model) Volume 4 Juli 2015. Technology Acceptance Model.

Xiao, J. J. (2008). Handbook of consumer finance research. Handbook of Consumer Finance Research, January 2008, 1-424. https://doi.org/10.1007/978-0-387-75734-6

Xiao, J. J., \& Porto, N. (2017). Financial education and financial satisfaction: Financial literacy, behavior, and capability as mediators. International Journal of Bank Marketing, 35(5), 805-817. https://doi.org/10.1108/IJBM-01-2016-0009

Yohana, I. (2010). Pengaruh Locus Of Control, Financial Knowledge, Income Terhadap Financial Management Behavior. Jurnal Bisnis Dan Akuntansi, 12(3), 131-144.

Zainul Arifin, A. (2018). Influence of financial attitude, financial behavior, financial capability on financial satisfaction. 186(INSYMA), 100-103. https://doi.org/10.2991/insyma18.2018 .25 